\title{
An insight into some innovative cycles for aircraft propulsion
}

\author{
G Corchero $^{1 *}$, J L Montañés ${ }^{1}$, D Pascovici ${ }^{2}$, and S Ogaji ${ }^{2}$ \\ ${ }^{1}$ Universidad Politécnica de Madrid (UPM), E. T. S. Ingenieros Aeronáuticos, Plaza Cardenal Cisneros, Madrid, Spain \\ ${ }^{2}$ Power and Propulsion Department, School of Engineering, Cranfield University, Cranfield, Bedfordshire, UK
}

The manuscript was received on 14 March 2008 and was accepted after revision for publication on 5 June 2008.

DOI: 10.1243/09544100JAERO346

\begin{abstract}
Emissions are important drivers in the design and use of aero-engines. This paper presents a part of the work carried out in the VITAL (EnVIronmenTALly aero-engine) project; it consists of a parameter study on the application of three innovative thermodynamic cycles to aircraft propulsion, looking for benefits on fuel consumption, carbon dioxide, nitrogen oxides, and noise. These cycles are intercooler-regenerative, the wave rotor topping, and the constant volume combustor cycles. The work, starting from a next-generation ultra-high bypass ratio turbofan, the baseline, and considering two possible design conditions, presents the influence of the application of these new cycles or design changes to the baseline on emissions and on the required technological level, represented by the turbine entry temperature (TET). VITAL is a project supported by the Sixth Framework Programme of the European Communities. The results show that some significant benefits on emissions can be achieved although they are linked to significant technology improvements and in-depth studies of the new components involved in cycle implementation.
\end{abstract}

Keywords: aero-engine, emissions, turbofan, innovative cycles, regenerative, intercooler, wave rotor, constant volume combustor, heat exchanger, ultra-high-bypass ratio

\section{INTRODUCTION}

Modern air transport has developed into a common means of travel. Apart from short-term fluctuations, the average worldwide growth in air travel is expected to continue at a rate of about 5 per cent per annum [1-3]. To some extent, the previous growth was enabled by the long-term development and application of advanced aero-engine technologies that focussed primarily on minimum fuel consumption as well as on manufacturing and maintenance economics.

Today, besides fuel consumption and manufacturing and maintenance economics some additional drivers have drastically increased the importance of improved aero engine technologies. They are the pollutants: the emissions, $\mathrm{NO}_{x}$, gases leading to green house effects, basically the $\mathrm{CO}_{2}$ measured by the

\footnotetext{
${ }^{*}$ Corresponding author: Universidad Politécnica de Madrid (UPM). E. T. S. Ingenieros Aeronáuticos, Plaza Cardenal Cisneros, 3, Madrid 28040, Spain.email: corchero@aero.upm.es
}

specific thrust fuel consumption (SFC) or the fuel consumed per unit of the thrust, and the noise generated by the engine components [1-7]; more efficient, economic, and environmental-friendly aero-engines are required worldwide. More efficient engines require the design of an aero-engine with higher thermal and propulsive efficiencies; any increase in the thermal efficiency or in the propulsive efficiency will bring down the SFC for a given flight velocity, which will also decrease the burnt fuel and $\mathrm{CO}_{2}$ production. The specific thrust (ST), which represents the amount of thrust per unit of airflow mass coming into the engine, is another important engine variable to be considered; it is a measure of the engine size, weight, and drag for conventional or near-conventional aeroengines, and it also influences the burnt fuel [8] and the noise emission. A higher ST lowers engine size. The development of more efficient and less polluting or environment-friendly aero-engines requires the maximum temperature and the overall pressure ratio of the cycle to be pushed up to improve their limits $[4,9,10]$ while curbing down the SFC and the 
nitrogen oxides, but also keeping in mind the current technology levels. Many studies have been carried out focusing on these general objectives, evolving from the standard Brayton cycle $[\mathbf{2}, \mathbf{4}, \mathbf{1 1 - 1 6}]$. Reference [6] presents interesting ideas on future revolutionary propulsion systems as micro propulsion systems integrated into the aircraft structure and aerodynamics, and also aircraft distributed fans driven by a central engine system. Reference [2] also presents additional ideas, including possible applications of non-aeroengine standard cycles as well as engine components improvement to increase engine efficiencies. Reference [11] also presents a nice comparison between interesting future candidate cycles.

Many European programmes, supported by the European Commission through their different framework programmes, are driven by these objectives; two of them are the CRYOPLANE, devoted to alternative fuels, hydrogen $[\mathbf{1 7}, \mathbf{1 8}]$, and the VITAL (environmental friendly aero-engine), under which programme the present work has been carried out [19]. The primary objective of the VITAL programme consists in developing the technology that permits the shortterm application of an optimized low-pressure turbine (LPT) spool, which drives a fan with an ultra-highbypass ratio (UHBR) and a booster in the engine core, and evolves from a previous fixed modern gas generator. Direct and gear drives as well as counterrotating fans are included. This translates into an improvement of the propulsive efficiency and also the possibility that the whole LPT spool weight would reduce. Looking to a long-term evolution, the VITAL project includes a task devoted to innovative cycles, which could improve engine efficiencies and emissions, although such cycles could come under nonconventional engine configurations; a part of the work carried out in this task is presented here.

This paper presents a work carried out, in the VITAL project, on the application of some innovative cycles to turbofan aero-engines with UHBRs (UHBRTF), bypass ratios above 12. Starting from the assumption that the LPT spool and the bypass stream have been optimized to get a maximum feasible propulsive efficiency and considering the expected technology improvement in the VITAL project, different innovative cycles have been applied to the engine core to improve performances. Performances are focused on SFC, and ST improvement, as well as on emissions and noise levels. In this study, the expected VITAL technology level is also considered as the baseline technology level.

\section{CANDIDATE CYCLES DESCRIPTION}

Recently, much work has been devoted to the analysis of innovative cycles and innovative components for aircraft propulsion systems. Reference [6] suggests some interesting ideas on future revolutionary propulsion systems as micro propulsion systems and aircraft distributed fans. Reference [2] also points out additional ideas, including possible applications of non-aero-engine standard cycles, whereas reference [11] presents a nice comparison between Brayton, PDE, and constant volume (CV) cycles. References [5] and [20] present the application of inter-stage turbine combustion and continuous turbine combustion cycles; the results show an important benefit of ST, but with an increase of SFC due to a lower propulsive efficiency, requiring therefore a new combustor-turbine technology. NASA has also devoted much work to the wave rotor simulation and development [14, 21-26]. Three cycles have received a special attention for their application to turbojets during in recent years. All are based on the application of some modifications to the standard Brayton cycle to obtain a higher efficiency by introducing new components. These cycles are: (a) intercooler-regenerative cycle (IRC), (b) the wave rotor topping cycle (WRTC), (c) the pulse detonation engine (PDE) cycle and the CV cycle or the Humphrey cycle, which really represents a first approximation to PDE cycle $[\mathbf{1 1}]$. This paper will be devoted to the study of these three cycles, searching for a performance improvement when they are applied to a next generation of turbofan engines as the VITAL engines are expected to be. The work will be based on their possible benefits to SFC, ST, emissions, and noise levels as well as to the improvements in technology. The following paragraphs present a brief description of each.

1. The IRC. In this cycle, the intercooler (IC), a heat exchanger, cools the mass flow coming into the high-pressure compressor (HPC), transferring energy from the engine core stream to the bypass stream at the exit of the outer fan (Fig. 1). This saves energy in the compression process, thereby improving the bypass contribution to the engine's ST, but additional fuel is required to obtain a given temperature at the exit of the combustor. This increase of fuel flow is compensated by an energy transfer from the exit of the LPT to the entrance of the combustor, the regenerative heat exchanger (RHE); the mechanical energy available at the exit of the LPT decreases smoothly producing an increase of thermal efficiency. It is a typical application in sea and terrestrial power generation [27-31], and in other special applications $[\mathbf{3 2}, \mathbf{3 3}]$. Some works can be found on the IRC application to aero-engines, especially in international symposia, including the development of heat exchangers for aero-engine applications [34, 35]. Finally, NEWAC (new aero-engine core concept) is also a European project devoted to the development of these technologies [36]. 

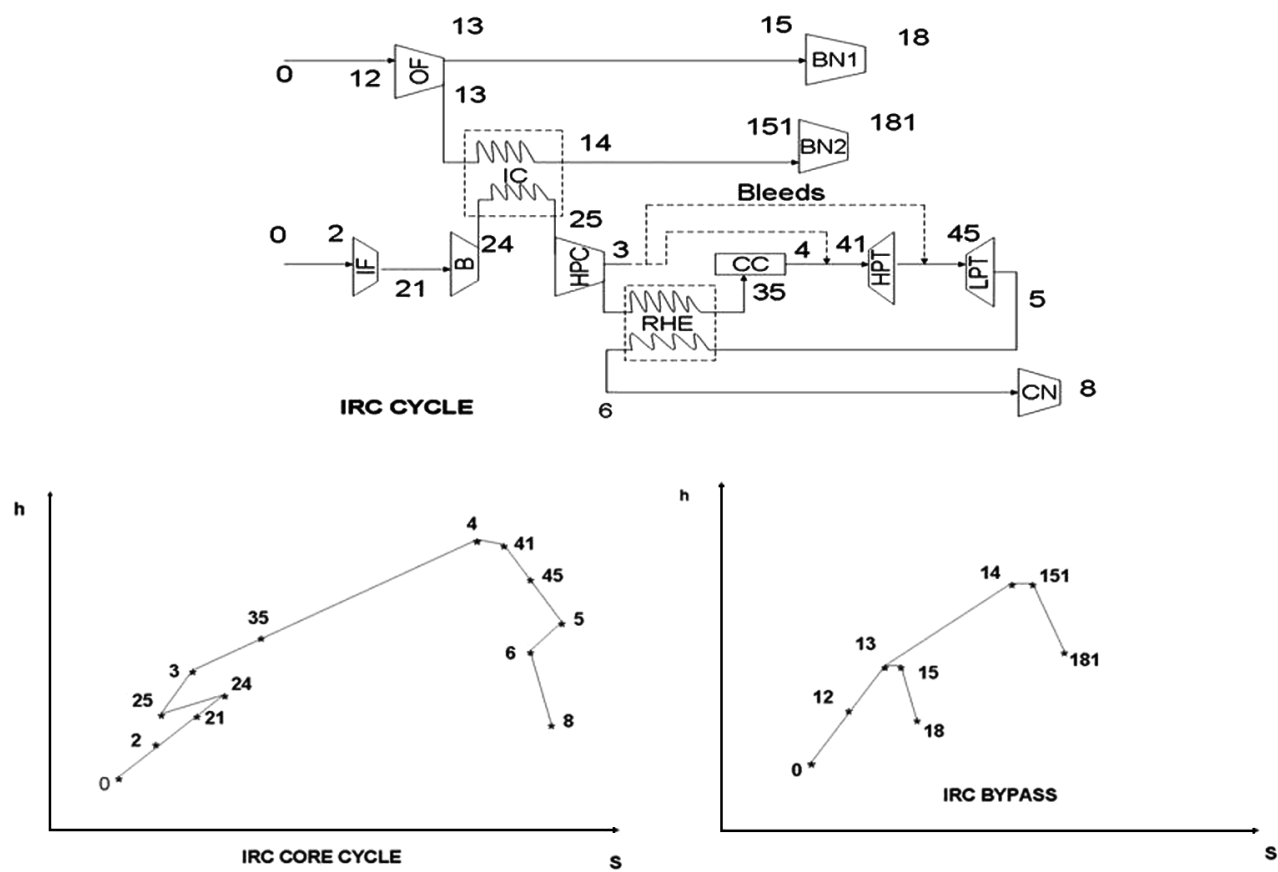

Fig. 1 IRC block and $h$ and $s$ diagrams

2. The WRTC. Wave rotors are devices that use unsteady waves to compress and expand air in a single device. The wave rotor consists of a duct or multiple ducts, near-parallel to the rotating axe, surrounded by a stationary casing; the casing end walls are penetrated by inlet and outlet ports that carry gas to and from the rotor passages or ducts. At any time, sectors of the rotor flow annuli are exposed to the ported flow while the remaining sectors face the casing end walls $[\mathbf{3 7}, \mathbf{3 8}]$. At the inlet port, low-pressure gas in the rotor passage is exposed to the high-pressure port flow; a compression wave compresses the passage gas and, thus, allows the incoming gas to enter the rotor. At the exhaust port, high-pressure passage gas is suddenly exposed to low-pressure exhaust port flow; an expansion wave propagates into the rotor passage, reduces the passage pressure, and discharges the passage gas into the exhaust port. The air, coming from the compressor, flows into the passage on the wave rotor, where it is compressed by compression waves and shock waves, it then leaves the wave rotor passing through the combustor (CC). From the combustor, the hot gas returns to the wave rotor and expands out to a lower pressure; passing through the wave rotor, the gases are first compressed and then expanded. Thus, a wave rotor combines in a single device the functions performed by a compressor and a turbine in a high spool (Fig. 2). Also, since the wave rotor is washed alternatively by cool air from the compressor and hot combustion gases, it is self-cooled, and permits the increase of the upper cycle pressure and temperature improving the thermal efficiency. NASA paid much attention to the wave rotor for aero-engine applications in the 1990s, including the design of demonstrators [23]. Also, during the last years, much work has been devoted to wave rotor studies [37-41].

3. The CV cycle. The constant volume combustor (CVC) cycle has also been studied due to its simplicity and as an estimate of the PDE cycle. The CV cycle replaces the standard combustor by a CVC; a small vessel or duct is fed with air coming from the compressor (Fig. 3). Once it is closed, the fuel is injected into the vessel and burnt; it is then opened and gases are discharged to the turbine entry. This combustor increases the cycle pressure, saving energy in the compression process, and saving also some HPC stages for the overall engine pressure ratio. References $[\mathbf{1 1}],[42]$, and [43] are devoted to interesting, related topics.

\section{PERFORMANCE MODEL}

The study has been applied to the short range gear turbofan (GTF) engine at sea level static (SLS) and International Standard Atmosphere plus $15^{\circ} \mathrm{C}(\mathrm{ISA}+15)$, and at cruise conditions ( $10668 \mathrm{~m}$ and $M_{0}=0.8$ ); hereafter, this engine will be referred as the baseline engine, and its values at the respective flight conditions will represent the reference values in this work. Similar qualitative and quantitative results are obtained when the study is applied to other VITAL engines as longrange engines, for example, to the long-range GTF 


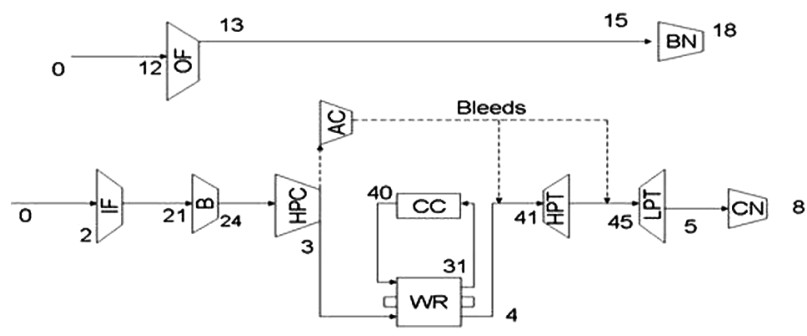

WAVE ROTOR BLOCK DIAGRAM
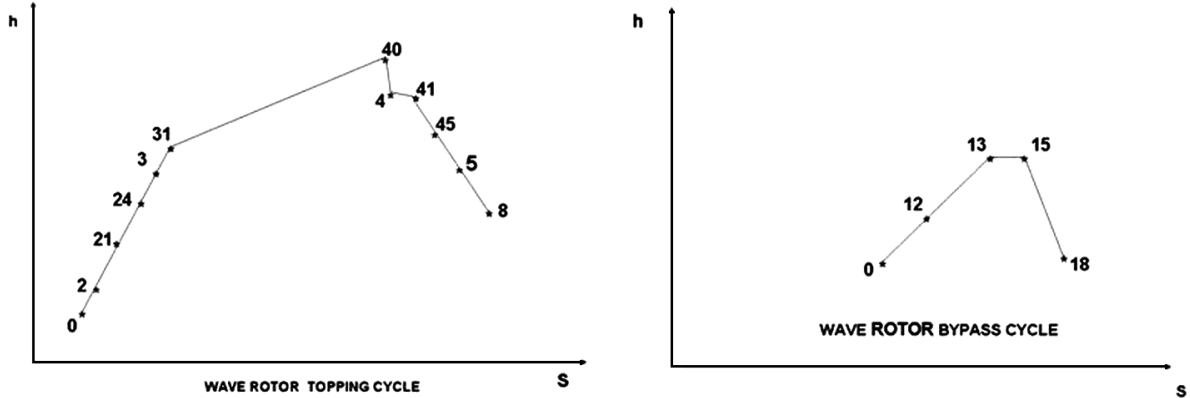

Fig. 2 WRTC block and $h$ and $s$ diagrams
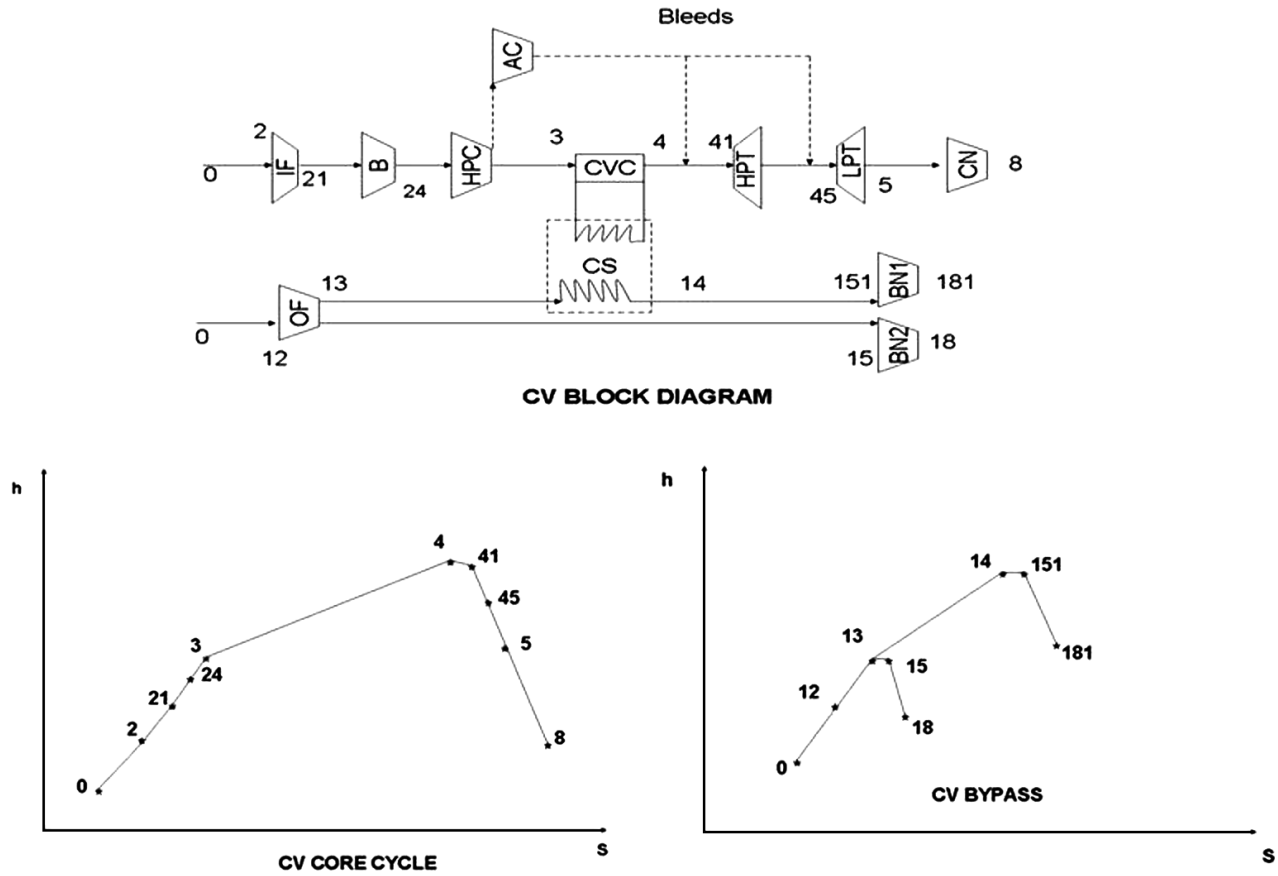

Fig. 3 CVC cycle block and $h$ and $s$ diagrams

engine. In the parameter study, it is assumed that bypass data (bypass ratio, outer fan pressure ratio, outer fan efficiency, and mass flow), booster data (pressure ratio and efficiency), and inner fan data (inner fan pressure ratio and inner fan efficiency) are constant and equal to the engine baseline values; they will represent the VITAL optimized LPT spool. Additionally, the bled air for turbine cooling is also assumed constant, justified by the constraint that the expected VITAL technology limit is assumed; this limit is represented by the TET value (the TET to the high-pressure turbine). All changes to the baseline engine, searching for an engine efficiency improvement, are applied to the core stream between the exit of the booster or intermediate pressure compressor (IPT) and the entrance of the core exit nozzle, with some interactions 
with the bypass stream at the exit of the outer fan. These cases are: (a) the IRC where the IC intercepts the core and bypass streams; (b) the CV where the bypass stream is used to cool the CVC (Figs 1 to 3 ).

The thermodynamic model for standard turbofans is well known and its description can be found in any text book or conceptual papers $[\mathbf{4 4 - 4 6}]$. As this work deals with real engines, it will also deal with enthalpy and entropy, considering that the transport coefficients change with the temperature, and that the composition and the air mass flow are changing along the engine. The influence of the fuel air ratio, far, the constant pressure specific heat, $\mathrm{C}_{\mathrm{p}}$, and the specific heat ratio, $\gamma$, and variations with temperature are considered. Figures 1 to 3 show the block and the $h-s$ diagrams of each cycle, where significant differences with respect to the standard Brayton cycle are present. The methodology applied to manage and study these differences are presented in next paragraphs.

1. The IRC. There are two important differences: (a) the IC heat exchanger; (b) the RHE (Fig. 1).

(a) The IC cools the whole core mass flow but only heat up a part of the bypass mass flow, $w_{\text {cool }}$, where $w_{\text {cool }}$ represents the ratio between the bypass-heated mass and the total bypass mass flow. A simple model has been applied to study the heat transfer process. The model assumes that both streams run in parallel until they reach the same temperature; this is equivalent to a mixing of two streams, with no heat addition and with the same composition; equivalent heat transfer could be obtained with a reasonable heat exchanger size by using a crossor a counter-flow heat exchanger. This condition along with the stagnation pressure losses at both heat exchanger sides, defines the exit conditions of both streams. Then, the bypassheated stream and the main bypass stream expand out to ambient conditions in two separate convergent nozzles, assuming the same stagnation pressure losses in both nozzles.

(b) The RHE is responsible for the energy transfer from the LPT exit to the combustor entry. It is defined by the stagnation pressure losses on both streams, cool and hot, and the regenerative thermal ratio or regenerative efficiency, $\eta_{\mathrm{R}}$, given by the expression (1)

$$
\eta_{\mathrm{R}}=\frac{T_{35}-T_{3}}{T_{5}-T_{3}}
$$

2. The WRTC. The WRTC represents the easiest case from a simulation point of view (Fig. 2). The wave rotor accomplishes the functions of a standard high spool, as such a high spool is usually simulated. Then, it will be considered as a standard high-pressure spool integrated by the compressor, standard combustor, and turbine [14].

3. The CV. In this case, the standard combustor and the HPC or some stages of the HPC are replaced by a CVC. The CVC is modelled as a vessel, that is filled with air, and once it is closed, some amount of fuel is added and burnt. The condition of constant volume leads to the expression

$$
\frac{P_{4}}{R_{4} T_{4}}=\frac{P_{3} k_{3} k_{4}}{R_{3} T_{3}}\left(1+\text { far }_{\mathrm{c}}\right)
$$

This expression links the $\operatorname{far}_{\mathrm{c}}$ in the combustor and the combustor entry and exit conditions, given by the pressure at the exit of the HPC, $\mathrm{P}_{3}$, the pressure at the exit of the combustor, $P_{4}$, before bleed mixing, and the gas constants at the respective sections. The constants $k_{3}$ and $k_{4}$ represent a measure of the pressure losses originated by the closing and opening combustor system, respectively. Therefore, the energy equation applied to the combustor leads to expression (3), which also links the entry and exit combustor conditions, and where $k_{\text {cool }}$ represents the ratio between the energy transferred to bypass by the CVC cooling process and the energy that can be obtained from the burnt fuel, $c$. FHV, where $c$ is the rate of the burnt fuel mass and FHV is its lower fuel heating value. $k_{\text {cool }}=0.10$ represents that 10 per cent of the energy coming from the burned fuel is transferred to the bypass in the cooling process

$$
h_{4}=\frac{\begin{array}{c}
\left\{h _ { 3 } + \text { far } _ { \mathrm { c } } \cdot \left[\mathrm{FHV} \cdot\left(1-k_{\mathrm{cool}}\right)\right.\right. \\
\left.\left.+C_{\mathrm{pf}} \cdot\left(T_{\mathrm{f}}-298.3\right)\right]\right\}
\end{array}}{1+\operatorname{far}_{\mathrm{c}}}
$$

In expression (3), $h_{4}$ and $h_{3}$ represent the stagnation enthalpies per unit of mass flowrate at the exit of the combustor and compressor, respectively, and $C_{\mathrm{pf}}$ is the constant pressure specific heat of the fuel, $T_{f}$ is its temperature at injection conditions, and $298.3 \mathrm{~K}$ is the standard temperature at which FHV is measured. Once the entry conditions, the pressure losses, far $_{c}$, the lower fuel heating value, and the transferred energy to the bypass are given, $k_{\text {cool }}$, the expressions (3) and (4) provide the combustor exit conditions.

The bypass stream coming from the exit of the outer fan is used to cool the CVC (CS in Fig. 3). Once it has cooled the combustor is expanded out to ambient conditions in a separate convergent nozzle as in the IC model. The enthalpy at the exit of the cooling process in accordance with the consideration made in the last paragraph, is given by

$$
h_{14}=h_{13}+k_{\mathrm{cool}} \cdot \operatorname{far}_{\mathrm{c}} \cdot \operatorname{FHV} \frac{w_{3}}{w_{14}}
$$

where $w_{3}$ is the mass, which goes through the CVC and $w_{14}$ is the mass flow of the bypass stream, 
$w_{14}=w_{\text {cool }} \cdot w_{12}$, which is used to cool the combustor. The influence of the mass flow $w_{14}$ on the engine performances is considered; $h_{14}$ and $h_{13}$ represent the stagnation enthalpies per unit of mass flow at the respective engine sections.

Additional considerations must be taken into account on cooling bleeds; it must be kept in mind that only the nozzle guide vanes (NGV) and the rotor of the HPT turbine require cooling air. These cooling airs are assumed constant, as in the baseline and was stated before, but they need some additional comments.

1. The IRC. There are three possibilities: (a) both bleeds are taken from the exit of the HPC or the entry of the RHE, (b) both bleeds are taken from the exit of the RHE, before the combustor entry, (c) one bleed is taken from the entry of the heat exchanger, the cooling air for the NGV of the HPT, and the other one from the exit of the heat exchanger. For the third case alone, some comments will be presented.

2. The CV and the WRTC. In both cases, the pressure at the exit of the HPC is usually lower than the pressure at the entry of the HPT turbine. An accessory pressure compressor (APC) will be used to increase the cooling air pressure, from the pressure at the bleed section to the value at the entry of the HPT.

3. Mixing process. The NGV cooling air is mixed with the main stream at the exit of the NGV, while the HPT rotor cooling air is mixed at the exit of the rotor. In both cases, the mixing is made at constant pressure, the stagnation pressure of the main stream, and assuming that the stagnation enthalpy is constant in the mixing process.

Some considerations must also be taken into account on emissions. First of all, the SFC is a measure of the $\mathrm{CO}_{2}$ production and a study of the SFC can be translated to $\mathrm{CO}_{2}$ emissions. Estimations of $\mathrm{NO}_{x}$, and noise level are complex tasks, requiring the knowledge of the components geometry, which is not known, especially in the case of a non-standard combustor; reference [9] presents a good summary on emissions. For $\mathrm{NO}_{x}$ emissions, the correlation from reference [47], which uses the pressure $\mathrm{P}_{3}$ in the combustor and the combustion temperature $T_{4}$, is used (expression (5)); it also offers qualitatively the same results as reference [48]. The author's data offer a good agreement with experimental data and conceptually they could be applied to any combustor; it must be kept in mind that the pressure and temperature, given $\mathrm{a} \mathrm{far}_{\mathrm{c}}$ value, represent a measure of the equilibrium composition. $P_{3}$ is expressed in MPa and $T_{4}$ in kelvin for $\mathrm{NO}_{x}$ calculation in expression (5). For the CV cycle, the pressure at the end of combustion process is considered.

Finally, in this study, only the noise due to the jets has been considered. The jet noise is a consequence of the fluid velocity at the nozzle exit; consequently, the ST is a measure of the noise. Then, the increase or decrease of the ST, in a first estimate, translates, respectively, into an increase or decrease of the noise level. The other components will be assumed as in the baseline or with minor changes depending on the case under study

$$
\mathrm{NO}_{x}=1.05 \cdot 10^{-6} P_{3}^{0.5} \mathrm{e}^{0.008 T_{4}}(\mathrm{ppmv})
$$

\section{RESULTS}

Different designs are possible starting from the shortrange GTF engine, the baseline engine, and once the new components are defined. These new components are defined by their characteristic parameters; an example could be the heat exchangers in the IRC. The RHE is defined by its regenerative efficiency and the stagnation pressure losses in both streams, while the IC is defined only by the stagnation pressure losses in both streams, core, and bypass; this can be inferred from the performance model. Two representative designs are considered: (a) design for constant TET, the same as in the baseline engine, and (b) design for constant ST, the same as in the baseline engine; in the first one, the VITAL technology limit for the gas generator is fixed, while in the second one the benefits of using lower TETs are also considered. These designs were done at two flight conditions: SLS and cruise, but no attempts have been made to match part loads, except for the IRC configuration. For both design conditions, the overall pressure ratio is the free parameter to fix the thermodynamic cycle, once the characteristic parameters that define that the new components are fixed; the influence of these characteristic parameters are presented in the next paragraphs. Section 4.1 presents the results for both design conditions at SLS (SLS ISA + 15) and section 4.2 shows the results for both design conditions at cruise $(10668 \mathrm{~m}$ and $M_{0}=0.8$ ). All the results presented in this paper are scaled by the reference values and any delta represents the difference between the variable under study and its respective reference value; these reference values correspond to the baseline engine values at the respective flight conditions, SLS ISA + 15 or cruise, depending on the flight conditions at which the parameter study is done.

\subsection{Results for designs at SLS}

\subsubsection{The intercooler-regenerative cycle}

Figures 4 to 9 present the results for constant ST designs and $w_{\text {cool }}=0.1$; this means that 10 per cent of the total bypass stream goes through the IC. This value increases the cycle possibilities of using an RHE 


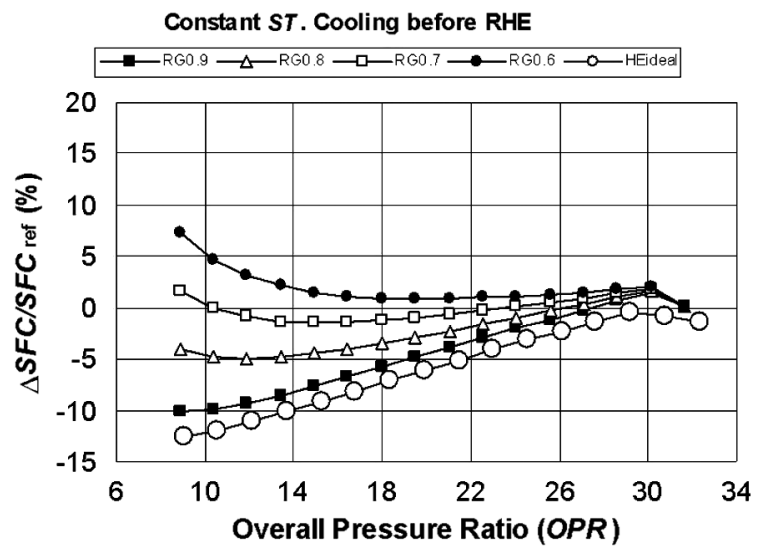

Fig. 4 Influence of the overall pressure ratio and the regenerative efficiency $(0.9, \ldots, 0.6)$ on SFC at SLS ISA +15 for constant ST design and cooling air bled before the RHE

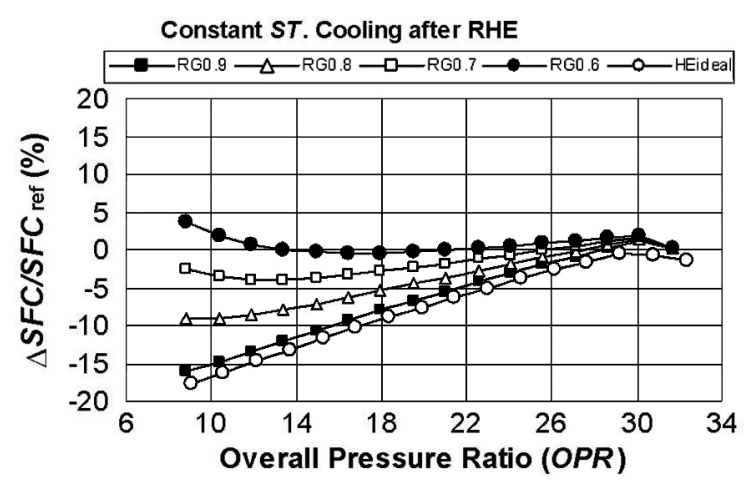

Fig. 5 Influence of the overall pressure ratio and the regenerative efficiency $(0.9, \ldots, 0.6)$ on SFC at SLS ISA +15 for constant ST design and cooling air bled at the exit of the RHE

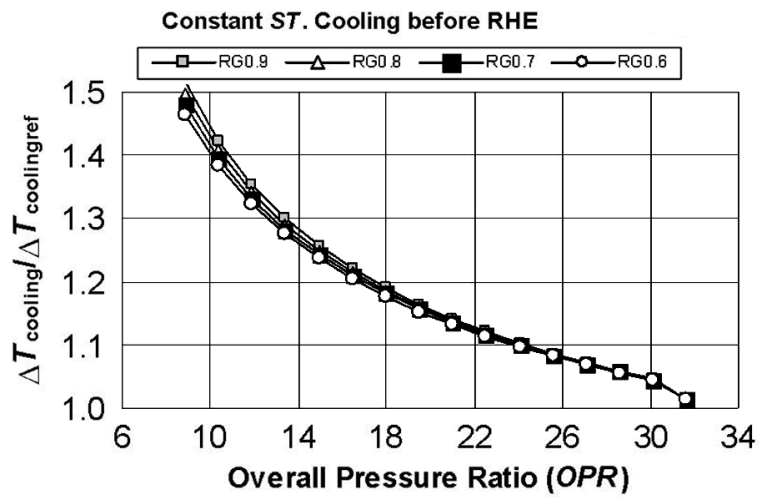

Fig. 6 Influence of the overall pressure ratio and the regenerative efficiency $(0.9, \ldots, 0.6)$ on cooling availability at SLS ISA +15 for constant ST design and cooling air bled before the RHE

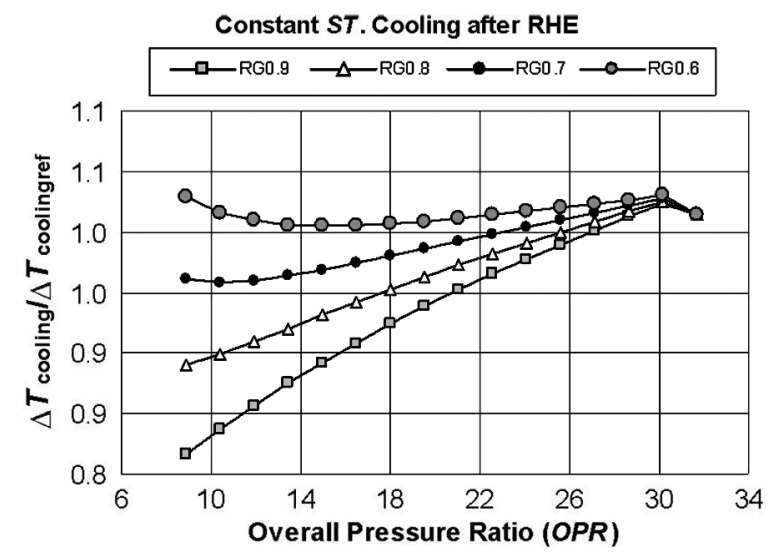

Fig. 7 Influence of the overall pressure ratio and the regenerative efficiency $(0.9, \ldots, 0.6)$ on cooling availability at SLS ISA+15 for constant ST design and cooling air bled at the exit of the RHE

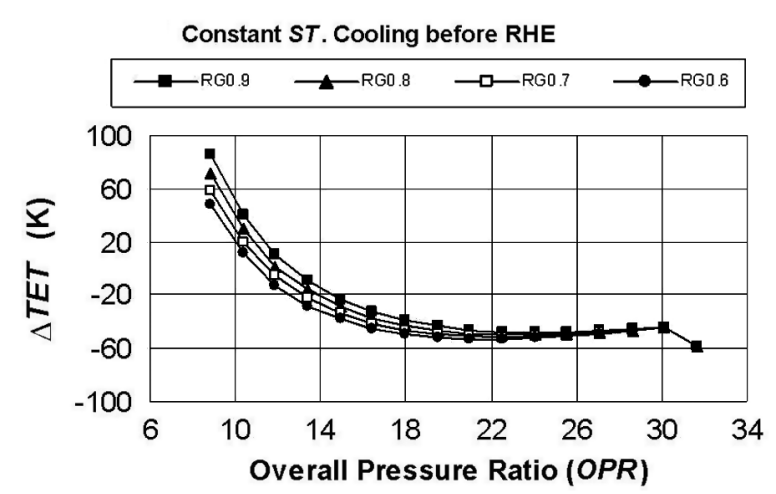

Fig. 8 Influence of the overall pressure ratio and the regenerative efficiency $(0.9, \ldots, 0.6)$ on TET at SLS ISA +15 for constant ST design and cooling air bled before of the RHE

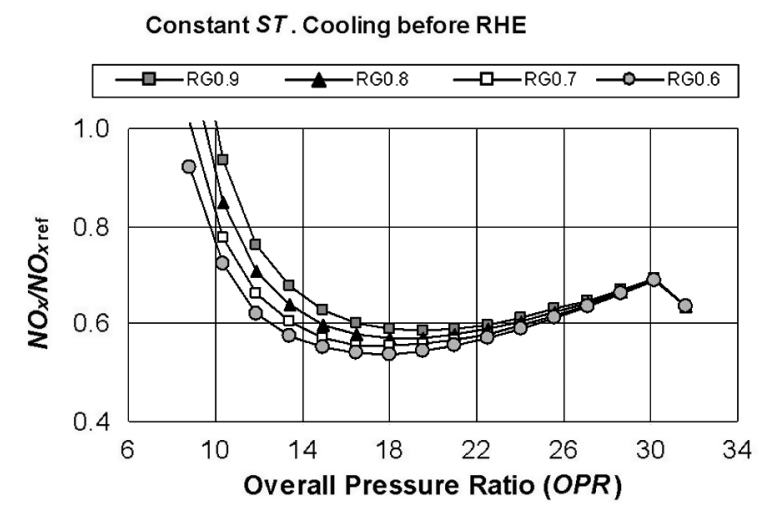

Fig. 9 Relative variation of $\mathrm{NO}_{x}$ emissions with the overall pressure ratio and the regenerative efficiency $(0.9, \ldots, 0.6)$ at SLS ISA +15 for constant ST design and cooling air bled before the RHE 
installed in the bypass; it also improves the ST capabilities of the engine; this possibility of using a RHE is also due to a lower HPC exit temperature as a consequence of a lower HPC entry temperature. Similar qualitative results will be obtained if this value is increased or decreased. The stagnation pressure losses are assumed to be the same for all the heat exchangers and equal to 3 per cent, which can be reasonable for SLS conditions [49]. These losses will increase if highly compact heat exchangers are used; in this way, a 1 per cent pressure loss increase in any heat exchanger will translate into an approximate increase of $0.1-0.2$ per cent in the SFC. Finally, the influence of the regenerative thermal ratio or regenerative efficiency is also included in the parameter study, with values ranging from 0.6 to 0.9 ; RG0.6, RG0.7, RG0.8, and RG0.9 in the different figures. Practically no benefits on SFC are obtained for $\eta_{\mathrm{R}}=0.6$ (Figs 4 and 5), while for $\eta_{\mathrm{R}}=0.9$ the maximum benefits on SFC are obtained. $\eta_{\mathrm{R}}=0.9$ represents a characteristic value in terrestrial applications, which will be difficult to achieve in aero-engines, and consequently, it would represent a target for aero-engine applications. The case of $\eta_{\mathrm{R}}=0.9$ and no stagnation pressure losses in the heat exchangers is also included as a reference and a measure of the maximum achievable benefits on SFC; it is called $\mathrm{HE}_{\text {ideal }}$ in the different plots.

Figures 4 and 5 show the benefits of SFC of both cooling bleed configurations and constant ST designs. These benefits vary from practically nil for $\eta_{R}=0.6$ to above 15 per cent for $\eta_{\mathrm{R}}=0.9$, and low overall pressure ratios when the cooling air is bled at the exit of the RHE. The higher benefits of this configuration come from the fact that the cooling air is bled at a higher temperature than when the cooling air is bled at the RHE entry, although this configuration could have dangerous effects on turbine cooling. Figures 6 and 7 show a measure of the ability of the cooling air to accomplish its function for both cooling configurations, respectively; they present the ratio of the temperature difference, $\Delta T_{\text {cooling }}$, between the temperature at the entry of the HPT NGVs and the temperature at the bleed section, and the same value for the baseline engine. Figure 6 shows a much higher $\Delta T_{\text {cooling }}$ than the baseline for the case of cooling air bled at the RHE entry, which would permit a decrease of cooling air mass flow and consequently obtain higher benefits for the SFC than the ones presented in Fig. 4. Figure 7, where the cooling air taken from the exit of the RHE, shows a clear loss of cooling ability for high RHE efficiencies, and low overall pressure ratios when the higher benefits for the SFC can be reached, so their benefits seem to be overestimated. These figures also show an important overall pressure ratio reduction, and the consequent decrease of the HPC size and weight for low SFC designs, overall pressure ratios of about 12 , and when it is compared with the baseline engine. Figures 8 and 9 also present additional benefits for TET and $\mathrm{NO}_{x}$ emissions for the case of cooling air bled at the RHE entry; practically, the same results are obtained in the case of cooling air bled at the exit of the RHE. For the case of maximum benefits for SFC, the engine TETs and $\mathrm{NO}_{x}$ emissions practically take the baseline engine values. For higher overall pressure ratios, however, when there are clear benefits for SFC and $\mathrm{NO}_{x}$ emissions, also there are clear benefits for TET, and consequently, on engine life (Figs 4, 5, and 8). A decrease of about $20^{\circ}$ on TET will double the turbine life. The same study has been carried out for the third cooling configuration and the results lead to the same conclusions; these results have not been included here to avoid an excessive data presentation.

Figures 10 and 11 present some results for constant TET designs. These results lead to the same conclusions as given previously with the difference that here there is a SFC benefit for ST, but also an increase

Constant TET. Cooling after RHE

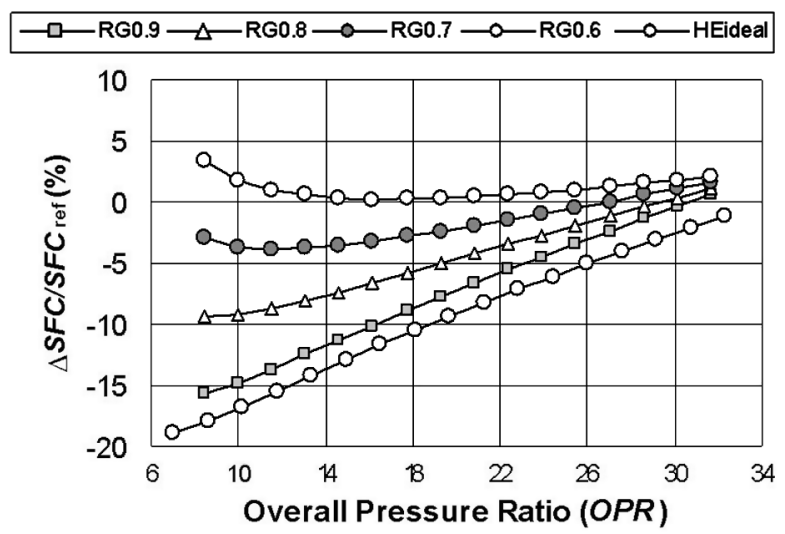

Fig. 10 Influence of the overall pressure ratio and the regenerative efficiency $(0.9, \ldots, 0.6)$ on SFC at SLS ISA +15 for constant TET design and cooling air bled at the exit of the RHE

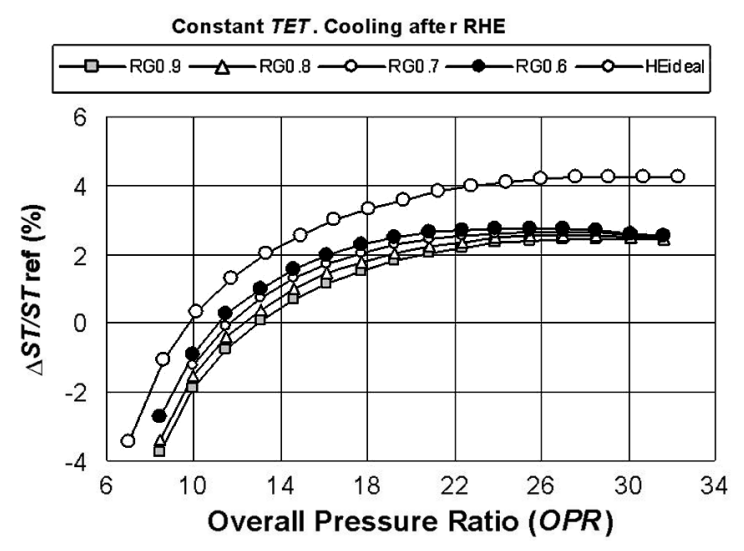

Fig. 11 Gain of ST with the overall pressure ratio and the regenerative efficiency $(0.9, \ldots, 0.6)$ at SLS ISA +15 for constant TET design and cooling air bled at the exit of the RHE 
of TET when compared with the results obtained for constant ST designs (Figs 8, 10, and 11). All cooling bleed configurations have been studied, as in the case of constant ST design, but not all results are presented to avoid excessive data and they would lead to the same conclusions.

\subsubsection{The WRTC cycle}

The WRTC is simulated as a standard turbofan cycle to which an extra standard high spool has been added, the wave rotor. An efficiency of 0.83 has been assumed for the compression and expansion processes [14], whereas the wave rotor pressure ratio has been varied from 1 to 3.6, a wave rotor pressure ratio that seems to be achievable $[14,15,22]$; the same efficiency has been assigned to the APC, used to compress the cooling air. Here also two design conditions, constant TET, and constant ST, have been considered.

Figures 12 to 16 show the results for both design conditions. This cycle significantly increases the

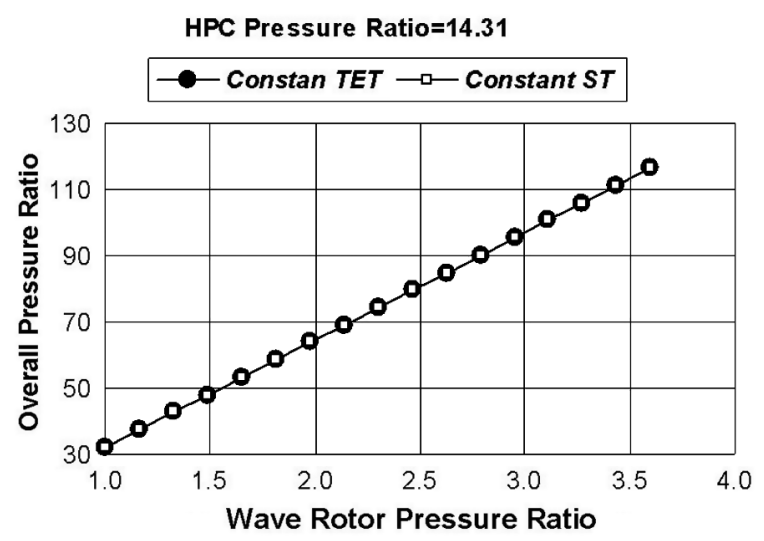

Fig. 12 Variation of overall pressure ratio with wave rotor pressure ratio for constant TET design (TET), and constant ST design (ST) at SLS ISA +15

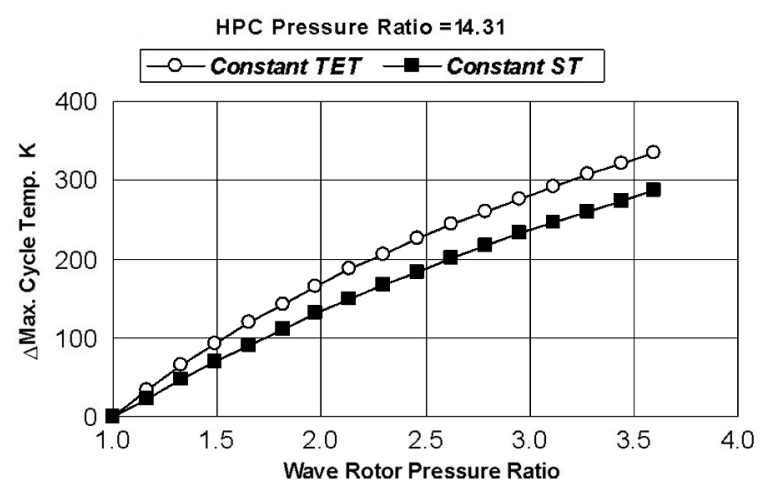

Fig. 13 Increase of maximum cycle temperature with the wave rotor pressure ratio for constant TET design (TET), and constant ST design (ST) at SLS ISA +15

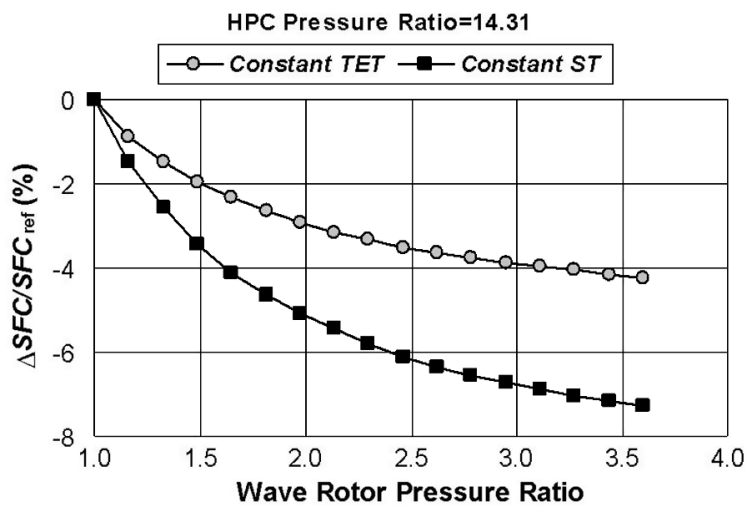

Fig. 14 Influence of the wave rotor pressure ratio on SFC at SLS ISA+15 for constant ST design (ST), and constant TET design (TET)

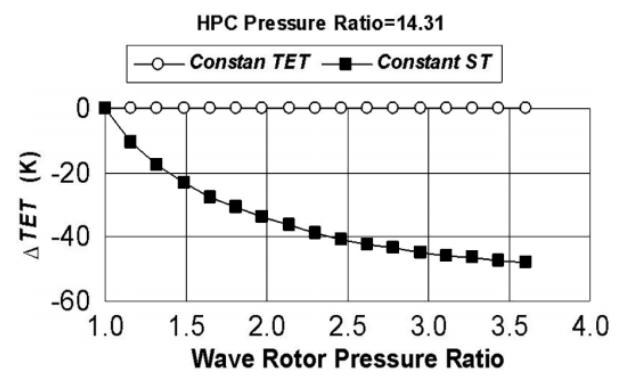

Fig. 15 Gain of TET with the wave rotor pressure ratio for constant TET design (TET), and constant ST design (ST) at SLS ISA+15

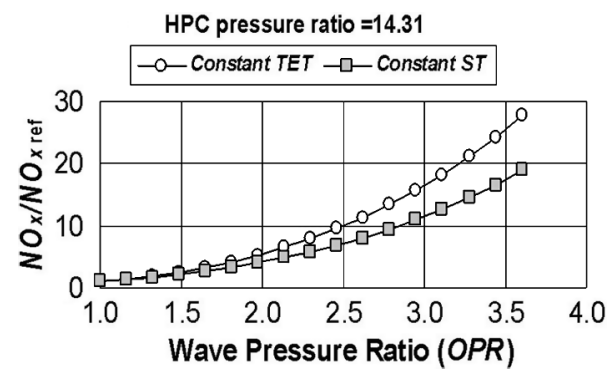

Fig. 16 Influence of the wave rotor pressure ratio on $\mathrm{NO}_{x}$ emissions, for constant TET design (TET) and constant ST design (ST) at SLS ISA+15

maximum cycle pressure and temperature (Figs 12 and 13), then, a thermal efficiency and SFC improvement is expected. Figure 14 presents the SFC improvement for both designs; for an achievable wave rotor pressure ratio of $2.5[\mathbf{1 4}, \mathbf{1 5}, \mathbf{2 2}]$, an improvement between 3 and 6 per cent is possible, depending on the design conditions. Additionally, while Fig. 14 presents a benefit of 3 and 6 per cent on SFC for constant TET and constant ST designs, respectively, Fig. 15 presents an important decrease of the TET for constant ST designs, which will translate into a clear increase of 
the engine life with no excessive increase of $\mathrm{NO}_{x}$ emissions (Fig. 16). The constant ST design shows a clear advantage over the constant TET design, getting higher benefits on SFC and also an important decrease of the TET. The increase of the maximum cycle pressure and temperature originates a clear increase of the $\mathrm{NO}_{x}$ emissions independently of the correlation used for its calculation (Fig. 16). Finally, assuming that the WRTC is self-cooled and consequently, the maximum cycle temperature is not a dramatic problem, it clearly increases the $\mathrm{NO}_{x}$ emissions, when compared with the baseline engine, and also provides lower benefits on SFC than the IRC.

\subsubsection{The CV cycle}

A steady process has been considered in the CV cycle simulation, although it is well known that the combustor discharge is an unsteady process; later we will come back to this process. Here only the design condition of a constant ST has been considered. The constant ST design gives a significant TET reduction, which means that a constant TET design does not make sense, and it will also lead to limited physical solutions.

In the CV simulation, it is assumed that 10 per cent of the total bypass mass flow is used in the CVC cooling process. This ensures the combustor cooling with a low temperature increase in the bypass stream, and IC installation in the bypass also seems to be feasible. It must be considered that this work deals with UHBRs and that the heat addition to a stream at low pressure is less efficient for mechanical energy production than heat addition to the core stream at a much higher pressure. Besides the HPC pressure ratio, the influence of the pressure losses at the combustor, $k_{3}$ and $k_{4}$, and the heat transfer to the bypass in the combustor cooling process have also been studied. Once the HPC pressure ratio is fixed, the design conditions will provide the overall pressure ratio. In the figures to be presented later, the symbol ST 0.080 .9 means that it corresponds to constant ST design and that 8 per cent of $c \cdot F H V$ is transferred to the bypass in the CVC cooling process and that 10 per cent of the stagnation pressure is lost in the opening and closing system, respectively, $k_{3}=k_{4}=0.9$. In fact, the product $k_{3} k_{4}$ is a parameter that represents the total stagnation pressure losses in the combustor, and it does not matter if these pressure losses are a consequence of the open $\left(k_{3}\right)$ or closing $\left(k_{4}\right)$ system (expression (2)); this is why for the simulation it is assumed that both $k_{3}$ and $k_{4}$ take the same value in an intent-of-plots reduction. Finally, to calculate the $\mathrm{NO}_{x}$ emissions (expression (5)), the pressure and the temperature at the exit of the combustor were used and the overall pressure ratio is defined as the ratio between the stagnation pressure at the exit of the combustor, once the pressure losses have been discounted, and the stagnation pressure at the entry of the engine, $P_{4} / P_{2}$.

Figures 17 to 21 present the results for the $\mathrm{CV}$ cycle. Figures 17 and 18 show significant benefits of SFC; these benefits are clearly lower than those of the IRC and practically equal to the benefits provided by the WRTC. These benefits go down when the HPC pressure ratio decreases, and consequently, the overall pressure ratio also decreases (Fig. 19), and also when the heat transfer to the bypass, due to the combustor cooling process or the pressure losses in the combustor, $1 / k_{3} k_{4}$, increases. The heat transfer to the bypass stream and the pressure losses could completely negate the benefits of SFC, or of $\mathrm{CO}_{2}$ production (Figs 17 and 18). In the case when combustor pressure losses increase, additional fuel is needed to compensate these pressure losses. In the case of an

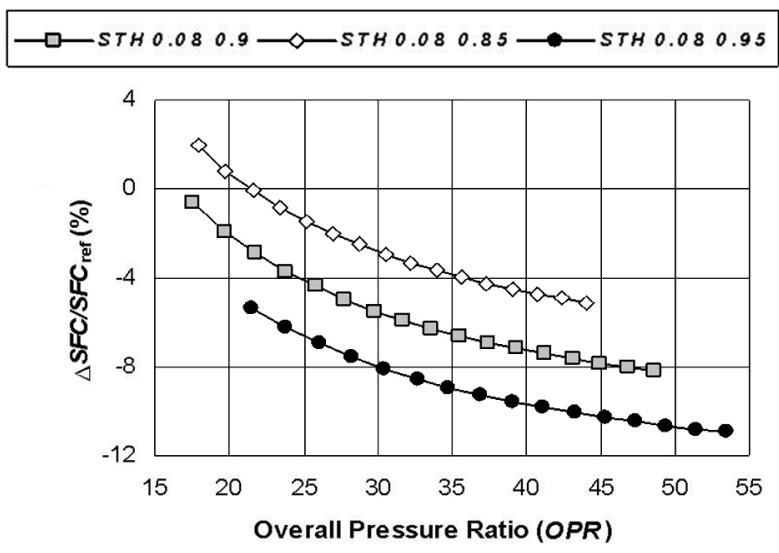

Fig. 17 Influence of the overall pressure ratio, and the combustor pressure losses on SFC for the CV cycle and constant ST design at SLS ISA+15

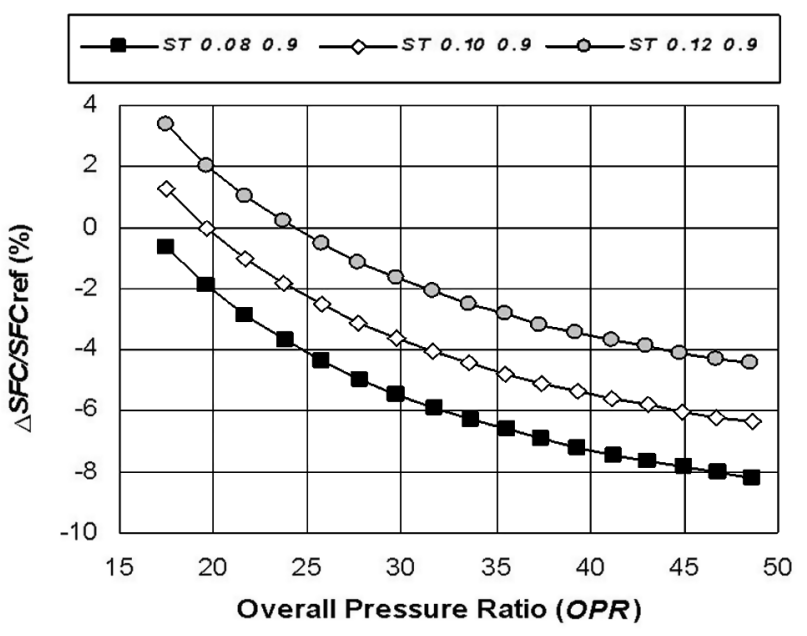

Fig. 18 Influence of the overall pressure ratio, and the heat transferred to the bypass in the combustor cooling process on SFC for the CV cycle and constant ST design at SLS ISA +15 

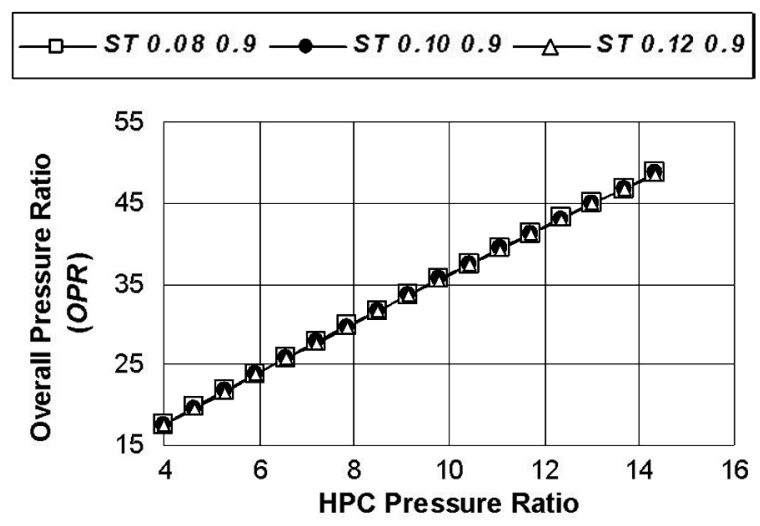

Fig. 19 Variation of the overall pressure ratio with the HPC pressure ratio for the CV cycle and constant ST design at S ISA +15

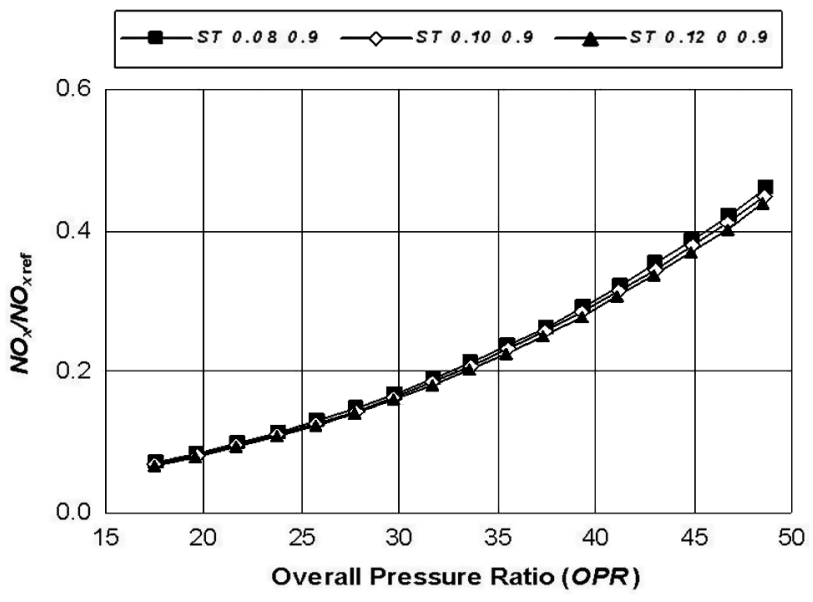

Fig. 20 Influence of the overall pressure ratio, and the heat transferred to bypass in the combustor cooling process on $\mathrm{NO}_{x}$ emissions for the $\mathrm{CV}$ cycle and constant ST design at SLS ISA+15

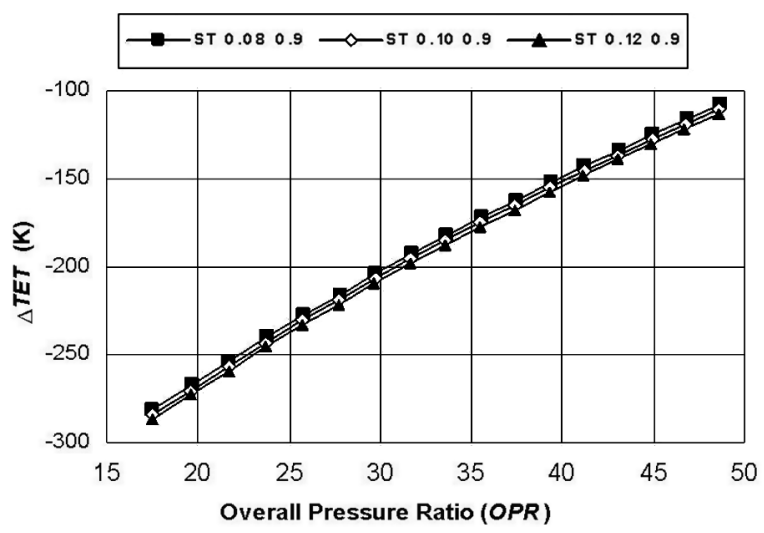

Fig. 21 Gain of TET with the overall pressure ratio and the heat transferred to bypass in the combustor cooling process for the CV cycle and constant ST design at SLS ISA +15 increase in the heat transferred to the bypass stream in the CVC cooling, the energy is transferred from the core stream at high pressure to a stream, the bypass stream, at a lower pressure, which is less efficient for mechanical energy production; the mechanical energy production will increase with the nozzle pressure ratio available in the different nozzles, core, and bypass streams.

Figures 20 and 21 show also some additional benefits of the CV cycle. These figures present the influence of the overall pressure ratio, indirectly the influence of the HPC pressure ratio, and the amount of heat transferred to the bypass in the combustor cooling process on the $\mathrm{NO}_{x}$ emissions and the TET. The CV cycle clearly reduces the working TET and consequently, also the cycle maximum temperature, with not much increase of the overall pressure ratio (Figs 19 and 21); the TET reduction will be of about $100 \mathrm{~K}$ to obtain the maximum benefits for SFC. This translates into a reduction of $\mathrm{NO}_{x}$ emissions (Fig. 20 and expression (5)), and also in a clear increase of the engine life. The influence of the amount of heat transferred to the bypass on TET is practically nil. Similar results are obtained if the influence of pressure losses in the combustor are considered, but it will be more sensitive to the pressure losses. This higher sensibility comes from the fact that the pressure losses affect the whole expansion process in the core stream and, as a consequence, a lower power is available to be given to the bypass stream through the fan compressor.

Globally, the CV cycle gives similar results on $\mathrm{NO}_{x}$ emissions when it is compared with the IRC, but benefits the SFC less. TET benefits are clearly higher than the ones obtained from the other cycles; any losses arising from the unsteady process have not been considered.

\subsection{Results for designs at cruise conditions}

The same parameter study carried out at SLS has been also done at cruise conditions to know if the same benefits, coming from the use of the three different cycles, can be obtained at these flight conditions. Starting from the baseline engine working point at cruise conditions (10 668 $\mathrm{m}$ and $M_{0}=0.8$ ), as in the study at SLS, two possible design conditions have been applied to the three different cycles under consideration. These conditions are the design for constant TET, the same as in the baseline engine at cruise and the design for constant ST, the same as in the baseline engine at cruise. In both cases, there must be benefits on SFC, emissions, and noise, and also if possible, on TET in the case of a design for constant ST. The variations of the different parameters, which define the new components in the three cycles and have been used in the study, coincide exactly with the variations used in the 
study at SLS with the exception of the pressure losses in the different heat exchangers. At cruise condition, the flow capacity of the heat exchangers will be lower than at SLS and consequently, because the pressure losses in a duct will be proportional to the square of the flow capacity [50], lower pressure losses are expected in the heat exchangers; these pressure losses are assumed to be constant and equal to 1 per cent instead of the 3 per cent assumed at SLS [49]. Therefore, taking into account that the results lead to the same considerations as in the study at SLS and to avoid an excessive presentation of data, only some relevant results are presented here.

Figures 22 to 24 present the SFC benefits obtained from the use of the three different cycles when they are compared with the baseline engine. Keeping in mind that the reference values are constant and correspond to the baseline engine at cruise working point; this could lead to the conclusion that at the maximum design overall pressure ratio, the SFC benefits for the IRC cycle are zero if the RHE cannot be installed because the temperature at the exit of the LPT is lower

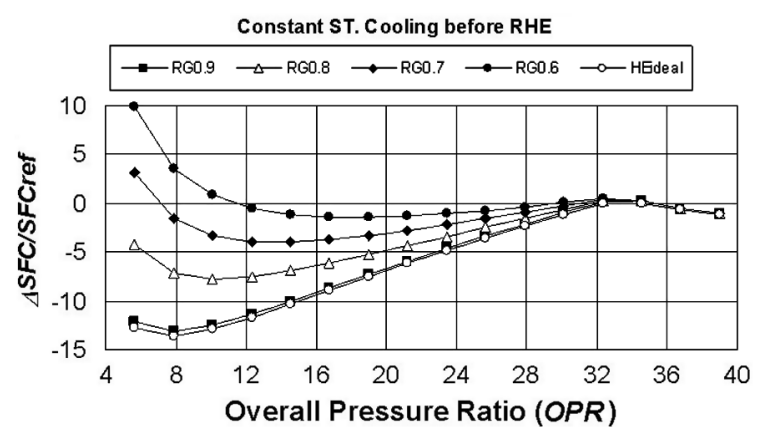

Fig. 22 Influence of the overall pressure ratio, and the regenerative efficiency $(0.9, \ldots, 0.6)$ on SFC at cruise, for constant ST design and cooling air bled at the entry of the RHE

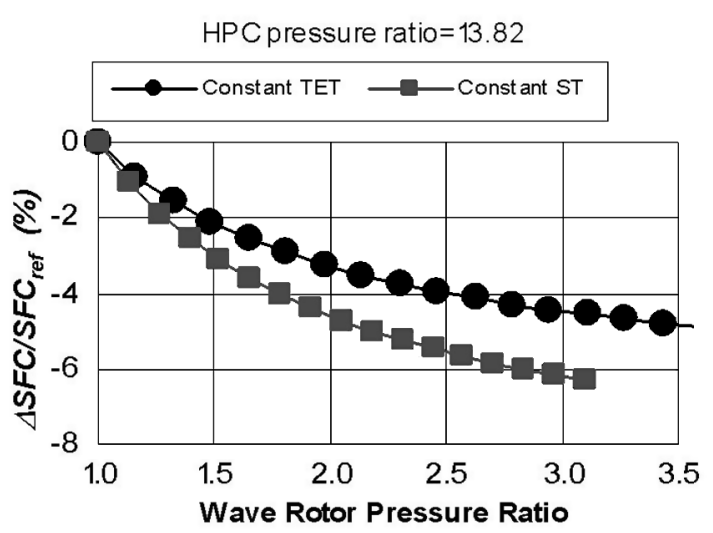

Fig. 23 Influence of the wave rotor pressure ratio on SFC at cruise, for constant ST and constant TET designs

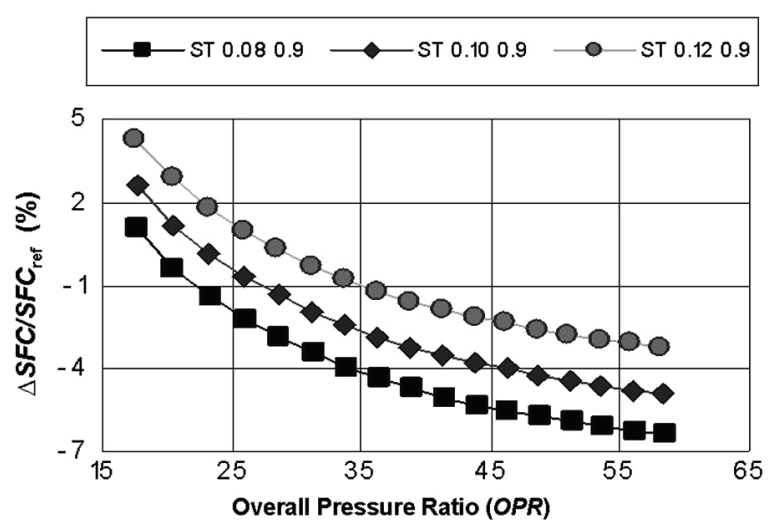

Fig. 24 Influence of overall pressure ratio and the combustor pressure losses on SFC for the CV cycle and for constant ST design at cruise

than the temperature at the exit of the HPC for that overall pressure ratio; this does not happen in the situation given in Fig. 22. This difference comes from the fact that there is also an IC heat exchanger, although there is no RHE.

These figures show similar benefits to the ones obtained in the study at SLS. These results were expected because, besides the parameters that define the new components and whose influence have been studied, the TET and the overall pressure ratio of the baseline engine really provide the possibilities of using some new components in the case of the IRC. There could also be power saving in the compression phase in the case of the $\mathrm{CV}$ cycle or the pressure ratio needed in the wave rotor to obtain the maximum benefits on thermal efficiency in the case of theWRTC. As an example, in the IRC, the overall pressure ratio of the baseline is lower at SLS than at cruise, while with the TET the opposite happens; this will not permit the use of a RHE at high design overall pressure at cruise, as can be seen in Fig. 22. In the IRC, the SFC first decreases and later increases with the design overall pressure ratio until it reaches a maximum, which represents the limit at which the RHE can be installed, and then starts to decrease again (Fig. 22). This last decrease of the SFC is a consequence of the increase in the overall pressure ratio and its influence on the thermal efficiency in a standard Brayton cycle. Finally, the same comments are pertinent to the rest of results that have not been presented to avoid an excessive data presentation.

\section{DISCUSSION}

The parameter study that has been presented offers relevant results from the point of view of fuel saving, $\mathrm{CO}_{2}$ production, as well as of $\mathrm{NO}_{x}$ emissions. An exception to $\mathrm{NO}_{x}$ emissions is the WRTC, which shows a clear increase in $\mathrm{NO}_{x}$ emissions due to a significant increase of the maximum pressure and temperature 
(Fig. 16). Other significant results correspond to possible designs with lower TETs for the case of a constant ST, which translates in an increase of the engine life and consequently, in manufacturing and maintenance economics, and also in emissions spinoff during the manufacturing and maintenance processes. The noise level due to jets will remain practically unchanged for a constant ST design, which also offers higher TET and SFC benefits. The turbomachineries remain the same or decrease their size, and consequently, no increase of noise is expected. For a constant TET, a low noise increase is expected as a consequence of the low increase of the ST, a measure of the jet velocities (Fig. 11).

Focusing on SFC, the range of benefits goes from about 3 to 6 per cent to above 15 per cent, depending on the design cycle and on the overall pressure ratio used in the design. The best benefits correspond to the IRC and the worse benefits correspond to the WRTC, while the CV is in between but closer to the IRC. A handicap in the CV cycle comes from the fact that a high-pressure loss is expected due to the closingopening combustor system; a possible configuration to compensate these pressure losses could consist in using a wave rotor with combustion inside the rotor. Additionally, the use of multiple ducts could also mitigate the problems due to the unsteady $\mathrm{CV}$ process. If the wave rotor would exactly compensate the assumed losses due to the combustor closing-opening system, the CV cycle would be transformed into an ideal CV cycle; this configuration will improve the SFC benefits and transform Fig. 17 into Fig. 25. Figure 25 shows the additional SFC benefits, which approach the benefits provided by the IRC. Considering the possible benefits on SFC alone, the IRC and the CV cycles promise similar values, while for a UHBRTF, the WRTC has clearly lower benefits; the IRC benefits go down when the design pressure ratio increases. From the point of view of $\mathrm{NO}_{x}$ emissions, the IRC and the $\mathrm{CV}$ provide clear benefits, decreasing these emissions, while the

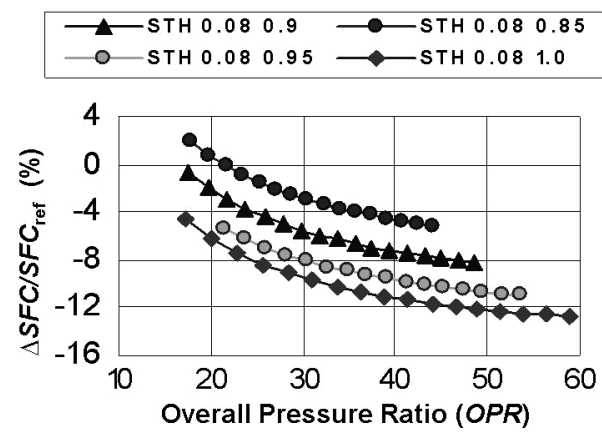

Fig. 25 Influence of the overall pressure ratio and the combustor pressure losses on SFC for the CV cycle, and constant ST design at SLS+15 and including also the ideal case (ST 0.08 1.0)
WRTC drastically increases the $\mathrm{NO}_{x}$ emissions; this is an important handicap of the WRTC.

An additional important benefit, presented in the previous section, consists in the possibility of using lower design TETs. These benefits are nil for the IRC and the designs for a minimum SFC, while they are high in the cases of WRTC and CV cycles, especially in the case of the CV cycle (Figs 8, 15, and 21). This TET benefit can also be relevant for the IRC, and for designs for higher overall pressure ratios and constant ST, but it will be offset by lower SFC benefits.

Finally, it is important to keep in mind that these benefits for the IRC come from the assumption of high regenerative efficiencies. The best situation corresponds to $\eta_{\mathrm{R}}=0.9$, a value difficult to achieve because of the size of the RHE required. The heat exchanger size can be an important drawback for its use in an aeroengine at the current technology level. Size means an increase of weight and volume, and the volume will translate in drag, and the increase of weight and drag will translate into an increase of the installed SFC, the fuel consumed per unit of the installed thrust, or the fuel consumed during a specified aircraft mission. The influence of the increase of weight and volume on the aircraft mission is an interesting work for the future; it will require the real design of the heat exchangers and linking of the engine and aircraft performances. Only the influence of assumed deltas of weight and drag will be considered here.

At this stage, the purpose of the work consists in estimating the possible benefits of the different innovative cycles that have been studied and ranking them for future development depending on their benefits. Focusing on these objectives, the sensitivity of the IRC to the increase of weight and drag has also been studied; this is the configuration when an increase of weight and drag is expected. The IRC configuration, assuming current technology for heat exchangers maps, allows computation of the off-design engine performances and to link them with the aircraft mission performances. Figures 26 and 27 present the influence of the assumed deltas of weight and drag on the total fuel burnt during the whole aircraft mission, and for three regenerative efficiency values; $\eta_{R}=0.7$ and $\eta_{\mathrm{R}}=0.9$ can represent the current and the target values, respectively. To estimate the weight and drag influence, the IRC design point is fixed at SLS ISA +15 for an overall pressure ratio of 14 , OPR $=14$, three $\eta_{\mathrm{R}}$ values and the design condition, constant ST, along with a reasonable value for the SFC (Fig. 4). The off-design performances are computed at any flight condition needed to be linked with aircraft performances. The TURBOMACH and HERMES codes have been used for off-design engine and aircraft performance calculations respectively, during the mission, and are applied to the baseline engine and the three IRC designs for the standard VITAL short-range aircraft 


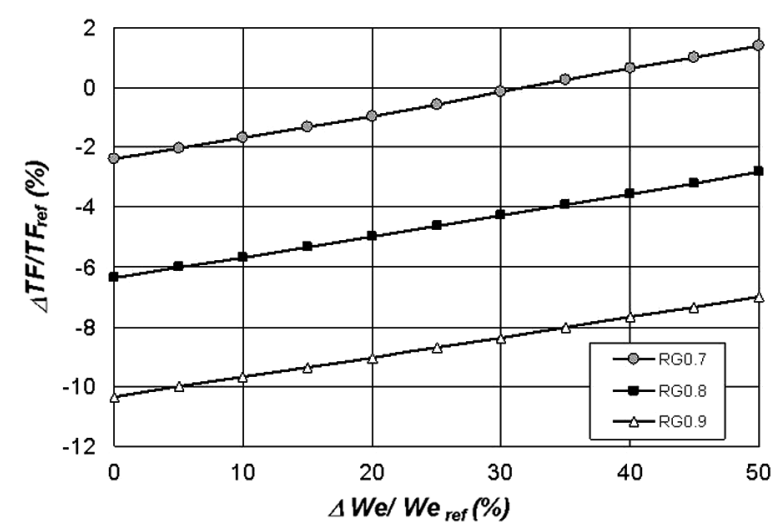

Fig. 26 Influence of the increase of weight on the total burned fuel during the whole aircraft mission, for three regenerative efficiencies $\left(\eta_{\mathrm{R}}=0.7,0.8\right.$, and 0.9); RG in the figure

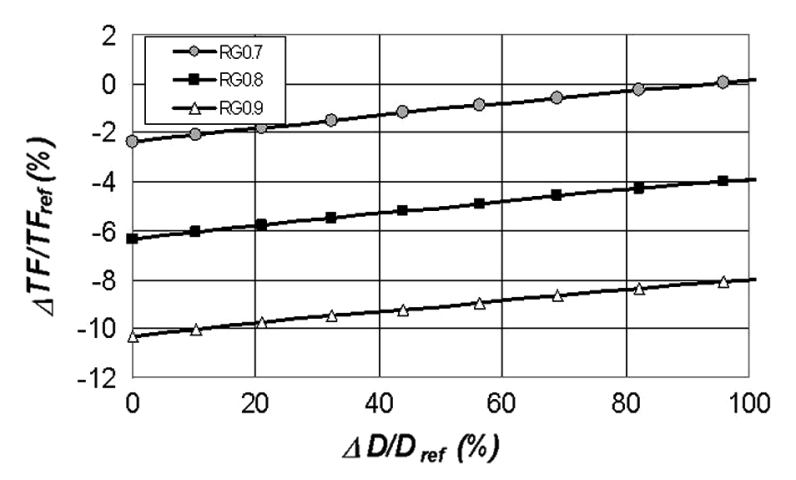

Fig. 27 Influence of the increase of drag on the total burned fuel during the whole aircraft mission, for three regenerative efficiencies $\left(\eta_{\mathrm{R}}=0.7,0.8\right.$, and 0.9); RG in the figure

mission. TURBOMACH and HERMES are codes developed and widely used at Cranfield University. These figures show that the final benefits, when using the IRC engines, will be highly dependent on the level of the heat exchanger technology, its regenerative efficiency, and its size; a low regenerative efficiency and a high heat exchanger size, volume and weight, can mitigate their benefits.

Figures 26 and 27 show that the increase in weight and drag can nullify all SFC benefits for $\eta_{\mathrm{R}}=0.7$. For $\eta_{\mathrm{R}}=0.8$, which could represent an achievable value with the appropriate technological development, major benefits can be obtained even for important increases in weight and size; a 100 per cent increase in drag translates into an increase of 41 per cent in the engine diameter, assuming that the drag varies linearly with the square of the engine diameter. The maximum benefits for total fuel consumption correspond to $\eta_{\mathrm{R}}=0.9$, but it represents a difficult value to be achieved even in terrestrial applications where the weight and size of the heat exchangers do not represent a critical constraint.

These results are really promising, but they need some additional considerations as given below.

1. The IRC. This cycle seems to be the most promising at the current technology level. In any case, there are three points that need to be considered.

(a) Small heat exchangers and high regenerative efficiencies are essential to obtain all shown benefits, but they really represent a difficult task and will require important further developments. The heat exchanger size and weight can clearly mitigate the benefits.

(b) Heat exchanger reliability and life are also an important concern in the IRC for aero-engine applications. Any heat exchanger failure could be critical in aircraft propulsion.

2. The WRTC. The WRTC is also unsteady as it happens with the CV cycle; this unsteadiness was solved using multiple ducts in the NASA studies. In any case, in-depth aerodynamic developments are needed to improve its efficiency and the achievable pressure ratio. Most of the recent publications on the wave rotor are devoted to the wave rotor aerodynamic studies [37-41].

3. The $C V$. This promises high benefits, but there are also matters of great concern. Some of these concerns are.

(a) The unsteadiness, which translates into a performance loss as well as into unsteady working conditions for the turbine, could also be an important drawback. Perhaps one way to avoid it could be the use of multiple chambers with some time delay between each; a solution similar to one used in the case of the wave rotor with multiple ducts.

(b) The cooling process. How can the cooling process be implemented? Fins immersed in the bypass stream as in air cooling reciprocating engines is one possibility. The value $k_{\text {cool }}=0.08$ was taken as a characteristic value from these kinds of engines [51].

(c) The combustion system. The combustion system is also a complex system to be studied. It will require further in-depth studies. References [25] and [26] are devoted to this crucial topic.

Summarizing, looking at future developments, and attending to the benefits for SFC and $\mathrm{NO}_{x}$ emissions, the IRC and the CV are located at a rather similar level, while the WRTC is clearly at a lower place, especially with regard to $\mathrm{NO}_{x}$ emissions. If the benefits for TET and the increase of weight and volume are considered, the CV seems to be above the IRC, although it is complicated to imagine the weight and volume of the CV at 
this stage. If the current technological level, it is possible to think that the IRC is located above the CV; the heat exchanger technology for terrestrial applications is well known. Finally, the WRTC seems to be a good option for small engines, with low overall pressure ratios, reaching high efficiency without high $\mathrm{NO}_{x}$ emissions.

\section{CONCLUSIONS}

This paper presents a parameter study on three different innovative cycles that could be applied to aircraft propulsion. These three cycles have been applied to a characteristic next-generation UHBR short-range aero-engine looking for a possible future evolution and searching for benefits on SFC emissions, and economics. The parametric study has been applied to SLS and cruise conditions, and considers two possible designs: (a) design for a constant ST; (b) a design for constant TET, considering the current technology level limit; both values correspond to the baseline engine at the respective flight conditions. The study leads to the following conclusions.

1. A significant decrease of SFC can be obtained for the three cycles. These benefits can reach values close to 15 per cent, depending on the cycle.

2. The benefits for SFC can also be translated into benefits for $\mathrm{NO}_{x}$ emissions. An exception is the WRTC, which increases $\mathrm{NO}_{x}$ emissions due to a high increase in the maximum cycle pressure and temperature.

3. The case of a design condition with a constant ST also leads to significant lower engine TETs, which would increase engine life. These benefits are extremely high in the case of the CV cycle.

4. The three cycles will need important technological developments, especially the WRTC and the CV cycle. The IRC seems to be the most achievable at the current technological level, as it comes from typical applications in sea and terrestrial power generation.

\section{ACKNOWLEDGEMENT}

VITAL is a new collaborative research project, running for four years, which aims to significantly reduce aircraft engine noise and $\mathrm{CO}_{2}$ emissions. It has a total budget of 90 million Euros, including 50 million Euros in funding from the European Commission. Snecma leads a consortium of 53 partners gathering all major European engine manufacturers: Rolls-Royce, MTU Aero-Engines, Avio, Volvo Aero, Techspace Aero Rolls-Royce Deutschland and ITP, and the airframer Airbus.
The work in this paper above was performed under WP 1.2 and Engine assessment/1.2.3 and Evaluation of Novel Propulsion Systems and Universidad Politécnica de Madrid (UPM) and Cranfield Univers ity (CU) specifically contributed to the work presented in the paper.

\section{REFERENCES}

1 Klug, H. G. and Reinhard, F. CRYOPLANE: hydrogen fuelled aircraft - status and challenges. Air Space Eur., 2001, 3(3), 252-254.

2 Howse, M. Rolls-Royce and gas turbine. In the 16th ISABE International Symposium on Air Breathing Engines, Cleveland, Ohio, USA, September 2003, AIAA paper 2003-1002.

3 Steffen, K. and Walter, R. Driving the technological edge in airbreathing propulsion. In the 16th ISABE International Symposium on Air Breathing Engines, Cleveland, Ohio, USA, September 2003, AIAA paper 2003-1002.

4 Nalim, R. M. and Resler Jr, E. L. Wave cycle design for wave rotor gas turbine engines with low $\mathrm{NO}_{x}$ emissions. J. Eng. Gas Turbine Power, 1996, 118, 474-480.

5 Sirignano, W. A. and Liu, F. Performance increases for gas-turbine engines through combustion inside the turbine. J. Propuls. Power, 1999, 15(1), 111-118.

6 Sehra, A. K. and Shin, J. Revolutionary propulsion systems for 21st century aviation. In the International Gas Turbine Congress 2003, Tokyo, Japan, 2-7 November 2003, paper IGTC03-ABS-066b, NASA TM-2003-212615.

7 Smith, C. P. The environmental challenge - bringing technology to market. In the 17th ISABE International Symposium on Air Breathing Engines, Munich, Germany, September 2005, paper ISABE-2005-1008.

8 Johnsen, A. and Bullock, R. O. Aerodynamic design of axial-flow compressors. NASA SP-36, 1965, ch. II.

9 Lefebvre, A. H. Gas turbine combustion, 1998 (Taylor \& Francis, Philadelphia, London).

10 Lefebvre, A. H. Fuel effects on gas turbine combustionliner temperature, pattern factor, and pollutants emissions. J. Aircr., 1984, 21(11), 887-898.

11 Heiser, W. H. and Pratt, D. T. Thermodynamic cycle analysis of pulse detonation engines. J. Propuls. Power, 2002, 18(1), 68-76.

12 Nalim, M. R. Thermodynamic limits of work and pressure gain in combustion and evaporation processes. J. Propuls. Power, 2002, 18(6), 1176-1182.

13 Cai, R. A new analysis of recuperative gas turbine cycles. Proc. Instn Mech. Engrs, Part A: J. Power and Energy, 1998, 212, 289-296.

14 Wilson, J. and Paxson, D. E. Jet engine performance enhancement through use of a wave-rotor topping cycle. NASA TM-4486, 1993.

15 Welch, G. E., Jones, S. M., and Paxson, D. E. Wave-rotorenhancement gas turbine engines. J. Eng. Gas Turbine Power, 1997, 119, 469-477.

16 Wilson, J. and Paxson, D. E. Wave rotor optimization for gas turbine engine topping cycles. J. Propuls. Power, 1996, 12(4), 778-785. 
17 Liquid Hydrogen Fuelled Aircraft - System Analysis (CRYOPLANE), Part B Proposal GRD1-1999-10014. Fifth Framework Programme of the European Communities, contract G4RD-CT-2000-00192, June 1999.

18 Corchero, G. and Montañes, J. L. An approach to the use of hydrogen for commercial aircraft engines. Proc. IMechE, Part G: J. Aerospace Engineering, 2005, 219, 3543.

19 Environmentally Friendly Aero Engine (VITAL). Sixth Framework Programme of the European Communities, contract AIP4-CT-2004-012271, 2004.

20 Liu, F. and Sirignano, W. A. Turbojet and turbofan engine performance increases through turbine burners. J. Propuls. Power, 2001, 17(3), 695-705.

21 Welch, G. E. Wave engine topping cycle assessment. In the 35th Aerospace Science Meeting and Exhibit, Reno, Nevada, January 1997, paper AIAA-97-0707, NASA TM107371.

22 Paxson, D. E. and Lindau, W. J. Numerical assessment of four-port through-flow wave rotor cycles with passage height variation. In the 33rd Joint Propulsion Conference and Exhibit, Seattle, Washington, July 1997, NASA TM107490.

23 Welch, G. E. and Paxson, D. E. Wave-rotor-enhanced gas turbine engine demonstrator. In the Gas Turbine Operation and Technology for Land, Sea and Air Propulsion and Power System Symposium, Ottawa, Canada, 18-21 October 1999, NASA TM-1999-209459.

24 Wilson, J. An experiment on losses in a three-port wave rotor. NAS CR-19508, 1997.

25 Nalim, M. R. Assessment of combustion modes for internal combustion wave rotors. J. Eng. Gas Turbine Power, 1999, 121, 265-271

26 Nalim, M. R. and Paxson, D. E. A numerical investigation of premixed combustion in wave rotors. In the 41st Gas Turbine and Aero Engine Congress, Birmingham, UK, 1013 June 1996, paper ASME-96-GT-116, NASA TM-107242.

27 Cohen, H., Rogers, G. F. C., and Saravanamamuttoo, H. I. H. Gas turbine theory, 1996 (Longman group, Harlow, UK).

28 Sawyer, W. J. Sawyer's gas turbine engineering handbook, 1972 (Gas Turbine Publications, Inc., Stamford, Connecticut, USA).

29 Dellenback, P. A. Improved gas turbine efficiency through alternative regenerator configuration. J. Eng. Gas Turbine Power, 2002, 124, 441-446.

30 Beck, D. S. Optimization of regenerated gas turbines. J. Eng. Gas Turbine Power, 1996, 118, 654-660.

31 Bhargava, R., Bianchi, M., Peretto, A., and Spina, P. R. A feasibility study of existing gas turbines for recuperated, intercooler, an reheat cycle. J. Eng. Gas Turbine Power, 2004, 126, 531-544.

32 Martinez-Frias, J., Aceves, S. M., and Brandt, H. thermodynamic analysis of zero-atmospheric emissions power plant. J. Eng. Gas Turbine Power, 2004, 126, 2-8.

33 Barrett, M. J. Expectations of closed-brayton-cycle heat exchangers in nuclear space power systems. J. Propuls. Power, 2005, 21 (1), 152-157.

34 Missirlis, D., Yakinthos, K., Palikaras, A., Katheder, K., and Goulas, A. Experimental and numerical investigation of flow field through a heat exchanger for aero-engine applications. Int. J. Heat Fluid Flow, 2005, 26, 440-458.

35 Yakinthos, K., Missirlis, D., Palikaras, A., Storm, P., Simon, B., and Goulas, A. Optimization of the design of recuperative heat exchangers in the exhaust nozzle of an aero-engine. Appl. Math. Model, 2007, 31(11), 2524-2541.

36 New Aero Engine Concept (NEWAC). Sixth Framework Programme of the European Communities, Proposa/contract no. FP6-030876, 2006.

37 Paxson, D. E. Numerical simulation of dynamic wave rotor performance. J. Propuls. Power, 1996, 12(5), 949957.

38 Welch, G. E. Macroscopic balance model for wave rotor. J. Propuls. Power, 1997, 13(4), 508-516.

39 Paxson, D. E. and Nalim, M. R. Modified throughflow wave-rotor cycle with combustor- bypass ducts. J. Propuls. Power, 1999, 151(3), 462-467.

40 Nagashima, T. and Okamoto, K. Simple numerical modelling for gasdynamic design of wave rotors. J. Propuls. Power, 23(1), 2007, 99-107.

41 Resler Jr, E. L., Moscari, J. C., and Nalim, M. R. Analytic design methods for wave rotor cycles. J. Propuls. Power, 1994, 10(5), 683-689.

42 Cambier, J. L. and Tegner, J. K. Strategies for pulsed detonation engine performance optimization. J. Propuls. Power, 1998, 14(4), 489-498.

43 Kentfield, J. A. C. Fundamentals of idealized airbreathing pulse-detonation engines. J. Propuls. Power, 2002, 18(1), 77-83.

44 Hill, P. G. and Peterson, C. B. Mechanics and thermodynamics of propulsion, 1965 (Addison-Wesley, London).

45 Mattingly, J. D., Heiser, W. H., and Prat, D. T. Aircraft engine design, AIAA Education Series, 2002 (American Institute of Aeronautics and Astronautics, Inc., Reston, Virginia).

46 Walsh, P. P. and Fletcher, P. Gas turbine performance, 1998 (Blackwell Science Ltd, London).

47 Lewis, G. D. A new understanding of $\mathrm{NO}_{x}$ formation. In the 10th ISABE International Symposium on Air Breathing Engines, Nottingham, UK, 1991, paper ISABE 91-7064.

48 Wulff, A. and Hourmouziadis, J. An universal combustor model for the predictions of pollutant emissions. In the 15th ISABE International Symposium on Air Breathing Engines, paper ISABE 99-7162, 1999.

49 Kentfield, J. A. C. Regenerative turbofans: a comparison with nonregerative units. J. Aircr., 1975, 12(3), 174-181.

50 Kays, W. M. and London, A. L. Compact heat exchangers, 1984 (Krieger Publishing Company, Malabar, Florida).

51 Ferguson, C. and Kirkpatrick, R. Internal combustion engines, applied thermosciences, 2001, ch. 8 (John Wiley \& Sons, Inc., New York).

\section{APPENDIX}

\section{Notation}

$B \quad$ booster (IPT)

BN1 main bypass nozzle 


\begin{tabular}{|c|c|}
\hline BN2 & heated stream bypass nozzle \\
\hline$c$ & fuel flow \\
\hline$C_{\mathrm{pf}}$ & fuel constant pressure specific heat \\
\hline$D$ & engine drag \\
\hline $\operatorname{far}_{\mathrm{c}}$ & combustion chamber fuel air ratio \\
\hline FHV & lower fuel heating value \\
\hline$h$ & enthalpy per unit of mass \\
\hline $\mathrm{HE}$ & heat exchanger \\
\hline$k_{\text {cool }}$ & $\begin{array}{l}\text { coefficient of heat transferred to } \\
\text { bypass }\end{array}$ \\
\hline$k_{3}$ & pressure loss at the CVC entry \\
\hline$k_{4}$ & pressure loss at the CVC exit \\
\hline$M_{0}$ & flight Mach number \\
\hline$P$ & stagnation pressure \\
\hline$R$ & gas constant \\
\hline
\end{tabular}

\begin{tabular}{|c|c|}
\hline RG0.8 & $\begin{array}{l}\eta_{\mathrm{R}} \text { representation on the figures, } \\
\text { including its value }(0.8)\end{array}$ \\
\hline$T$ & temperature \\
\hline$T_{\mathrm{f}}$ & total fuel consumed during the mission \\
\hline$w$ & mass flow \\
\hline $\begin{array}{l}w_{\text {cool }} \\
W_{\mathrm{e}}\end{array}$ & $\begin{array}{l}\text { coefficient of bypass heated mass } \\
\text { engine weight }\end{array}$ \\
\hline \multicolumn{2}{|c|}{ Subscripts } \\
\hline C & combustion chamber \\
\hline $\mathrm{f}$ & fuel \\
\hline ref & $\begin{array}{l}\text { reference values, provided by the short } \\
\text { range GTF }\end{array}$ \\
\hline $\mathrm{R}$ & regenerative heat exchanger \\
\hline $0,2,151$ & engine sections \\
\hline
\end{tabular}

